\title{
PERENCANAAN STRUKTUR Gedung PERKANTORAN DENGAN SISTEM RANGKA PEMIKUL MOMEN KHUSUS BERDASARKAN SNI 2847-20 13 DI BANTUL - YOGYAKARTA
}

\author{
Sonif Muafandi ${ }^{1)}$, Arifien Nursandah', Bambang Kiswono \\ 1) Program Studi Teknik Sipil, Fakultas Teknik, \\ Universitas Muhammadiyah Surabaya \\ Jl. Sutorejo No. 59 Surabaya, 60113 \\ Email: Sonifmuafandi22@gmail.com \\ ${ }^{2)}$ Program Studi Teknik Sipil, Fakultas Teknik, \\ Universitas Muhammadiyah Surabaya \\ Jl. Sutorejo No. 59 Surabaya, 60113 \\ Email: Arifien.nursandahums@gmail.com \\ 3) Program Studi Teknik Sipil, Fakultas Teknik, \\ Universitas Muhammadiyah Surabaya \\ J1. Sutorejo No. 59 Surabaya, 60113 \\ Email: BambangKiswono@gmail.com
}

\begin{abstract}
The design of reinforced concrete structures in the structure of PT. Indomarco Prismatama's office buildings in Bantul aimed to find out. (1) Dimensions of beams and columns that can withstand earthquake loads. (2) Detailed image of beam reinforcement and column from planning results.

In this final project, the structure of reinforced concrete building was planned by using the Special Moment Resisting Frame System (SRPMK) SNI 2847- 2013. Where the building of the Special Moment Resisting Frame System (SRPMK) used Strong Column and Weak Beam. The planned structure was a 6-story office building that was reviewed by using spectrum response analysis.

In the Special Moment Resisting Framework System that showed beams B1 (400x600) with $\rho=2.06 \%$; beam B2 (350x500) with $\rho=2.17 \%$; beam Ba1 (250x350) with $\rho=2.17 \%$; Ba2 beam (200x300) with $\rho=2.53 \%$; Column K1 (600x600) with $\rho=$ $2.18 \%$; K2 (500x500) column with $\rho=2.43 \%$;
\end{abstract}

Keywords: Building Structure, SRPMK, strong column weak beam.

\begin{abstract}
Abstrak
Perancangan struktur beton bertulang pada struktur bangunan perkantoran PT.Indomarco Prismatama diBantul ini bertujuan untuk mengetahui. (1) Dimensi balok dan kolom yang mampu menahan beban gempa. (2) Gambar detail penulangan balok dan kolom dari hasil perencanaan.

Dalam tugas akhir ini akan direncanakan struktur gedung beton bertulang menggunakan Sistem Rangka Pemikul Momen Khusus (SRPMK) SNI 2847- 2013. Dimana bangunan model Sistem Rangka Pemikul Momen Khusus (SRPMK) akan menggunakan Strong Column and Weak Beam (kolom kuat dan balok lemah). Struktur yang akan direncanakan adalah gedung perkantoran 6 lantai yang ditinjau dengan menggunakan analisa respons spektrum

Pada Sistem Rangka Pemikul Momen khusus, diperoleh balok B1 (400x600) dengan $\rho=2.06 \%$; balok B2 (350x500) dengan $\rho=2.17 \%$; balok Ba1 (250x350) dengan $\rho=2.17 \%$; balok Ba2 (200x300) dengan $\rho=2.53 \%$; Kolom K1 (600x600) dengan $\rho=$ $2.18 \%$; Kolom K2 (500x500) dengan $\rho=2.43 \%$;
\end{abstract}

Kata kunci : Struktur Gedung, SRPMK, strong column weak beam.

\section{PENDAHULUAN}

\section{Latar Belakang}

Peningkatan prasarana gedung perkantoran sangat diperlukan sejalan dengan semakin pesatnya pertumbuhan sosial ekonomi pada hampir seluruh wilayah diIndonesia khususnya di wilayah Bantul - Yogyakarta. Sehingga pembangunan prasarana gedung perkantoran sangat menentukan dalam menunjang tercapainya laju pertumbuhan ekonomi. Yogyakarta merupakan daerah rawan gempa, hal ini dikarenakan dilewatinya jalur gempa Megatrust pulau jawa, oleh sebab itu didalam merencanakan gedung harus direncanakan tahan terhadap gempa.

Dalam perencanaan gedung terdapat beberapa metode analisis seperti metode statik ekuivalen dan metode dinamis. Perencanaan gedung tersebut sudah dijelaskan di SNI 2012 pasal 12, yang berbunyi “ struktur dengan isolasi seisemik, kecuali yang ditentukan di 12.4.1, harus direncanakan dengan menggunakan prosedur dinamis". 12.4.1 Prosedur gaya leteral ekivalen di 12.5 boleh digunakan untuk perencanaan struktur dengan isolasi seisemik dengan ketentuan sebagai berikut:

1. Struktur terletak disitus dengan s1 kurang atau sama dengan $0,6 \mathrm{~g}$

2. Struktur terletak pada kelas situs SA, SB, SC, atau SD

3. Tinggi struktur diatas pemisah isolasi kurang atau sama dengan 4 lantai atau $19.8 \mathrm{~m}$ dari tinggi struktur, $\mathrm{hn}$

4. Periode efektif struktur dengan isolasi pada perpindahan maksimum, Tm kurang atau sama dengan 3.0 detik

5. Periode efektif struktur dengan isolasi pada perpindahan rencana, TD lebih besar dari 3 periode 
elastic struktur terjepit dari struktur diatas system isolasi,

6. Konfigurasi struktur diatas system isolasi adalah beraturan

7. Sistem isolasi harus memenuhi semua kriteria sebagai berikut

- Kekakuan efektif system isolasi pada perpindahan rencana lebih besar dari 1/3 kekakuan efektif pada saat $20 \%$ perpindahan rencana

- Sistem isolasi mampu menghasilkan suatu gaya pemulih

- Sistem isolasi tidak membatasi perpindahan gempa maksimum yang dipertimbangkan lebih kecil dari perpindahan maksimum total.

Dari data yang didapat, gedung perkantoran PT.INDOMARCO PRISMATAMA mempunyai spesifikasi bangunan dengan tinggi $23 \mathrm{~m}$ dan salah satu gedung yang mempunyai bentuk tidak beaturan. Berdasarkan pertimbangan yang telah dikemukakan di atas, maka pada Tugas Akhir ini saya merencanakan gedung perkantoran enam lantai dengan metode analisis dinamis menggunakan metode Respons spektrum analisis dengan sistem rangka pemikul momen khusus.

\section{Rumusan Masalah}

Masalah-masalah yang akan dibahas dalam penyusunan Tugas Akhir ini dapat dirumuskan sebagai berikut:

1. Bagaimana mengetahui konsep-konsep dasar perencanaan struktur bangunan tahan gempa berdasarkan SNI 2847 - 2013?

2. Bagaimanakah hasil gambar detail penulangan kolom, balok, plat serta tangga berdasarkan point satu?

3. Bagaimana merencanakan perhitungan struktur dengan tingkat keamanan yang memadai berdasarkan SNI 2013?

\section{Tujuan Penelitian}

Tujuan yang ingin dicapai dalam penelitian ini :

1. Mahasiswa bisa mengetahui konsep dasar perencanaan bangunan tahan gempa berdasarkan SNI 2847 - 2013

2. Mahasiswa dapat menggambar detail penulangan pada bangunan tersebut

3. Mahasiswa mampu merencanakan perhitungan struktur gedung dengan tingkat keamanan yang memadai.

\section{Manfaat Penelitian}

Manfaat yang diperoleh dari penelitian ini:

Penyusun diharapkan dapat memperoleh pengalaman pengetahuan dan wawasan perencanaan struktur bangunan gedung, disamping itu juga untuk merealisasikan semua ilmu yang berkaitan dengan teori dan perencanaan struktur yang diperoleh selama kuliah di Prodi Teknik Sipil, Fakultas teknik Universitas Muhammadiyah Surabaya.

\subsection{Batasan Penelitian}

Mengingat keterbatasan waktu dan kemampuan penyusun, dalam perencanaan Tugas Akhir ini, permasalahan penyusun dibatasi sebagai berikut :

1. Perencanaan terbatas pada struktur utama gedung.

2. Stuktur gedung dari beton bertulang

3. Rencana Anggaran Biaya (RAB) tidak diperhitungkan.

4. Asumsi hubungan pondasi, sloof, balok, kolom dan pelat beton merupakan tumpuan jepit

Untuk menjawab permasalahan yang ada, maka dilakukan perencanaan struktur.

Adapun pokok bahasan Tugas Akhir ini adalah :

1. Perencanaan Balok

2. Perencanaan pelat

3. Perencanaan Kolom

4. Perencanaan Tangga

5. Perencanaan Sloof

6. Perencanaan Pondasi

Untuk sarana penunjang seperti : instalasi listik, instalasi air, instalasi telepon, dan lain-lain tidak ikut dibahas. Hanya berat dari masing-masing bagian telah diperhitungkan dalam pembebanan. Dari data-data dan perhitungan, maka dapat ditentukan besarnya gaya mekanika dan untuk mempercepat perhitungan tersebut digunakan bantuan komputer dengan menggunakan program SAP 2000 vs 14

\section{TINJAUAN PUSTAKA \\ Beton Bertulang}

Beton bertulang mempunyai sifat sesuai dengan sifat bahan penyusunnya, yaitu sangat kuat terhadap beban tarik maupun beban tekan. Beban tarik pada beton bertulang ditahan oleh baja tulangan, sedangkan beban tekan ditahan oleh beton. Berdasarkan Pasal 8.5.2 SNI 2847-2013 modulus elastisitas baja tulangan nonprategang Es dapat diambil 200000 Mpa. Sedangkan pada Pasal 8.5.1 SNI 2847-2013 modulus elastisitas beton normal ditentukan berdasarkan: $E c=4700 \sqrt{ } f c^{\prime}$

\section{Sistem Rangka Pemikul Momen (SRPM)}

Sistem Rangka Pemikul Momen (SRPM) merupakan komponen struktur yang mampu memikul gaya akibat beban gempa dan direncanakan untuk memikul lentur. Terdapat tiga jenis sistem rangka pemikul momen yaitu:

Sistem Rangka Pemikul Momen Khusus (SRPMK), digunakan untuk kategori desain seismik B, C, D, E, dan F (KDS B, C, D, E, dan F).

\section{METODE PENELITIAN \\ Waktu dan Lokasi Penelitian}

Pada penelitian ini dilakukan pada proyek pembangunan gedung PT. Indomarco Prismatama, terletak di jl.raya imogiri siluk kab Bantul - Yogyakarta. Struktur gedung beton bertulang dengan lebar 62 meter dan panjang 24 meter ketinggian gedung adalah 23 meter yang terdiri dari 6 lantai, Tinggi lantai dasar adalah 4 meter dan tinggi lantai 2-6 adalah 3,5 meter. Fungsi 
utama bangunan adalah sebagai office area yang dilengkapi dengan sarana pendukung

\section{Pengumpulan Data}

Dalam membuat suatu analisa, diperlukan datadata sebagai bahan acuan. Untuk dapat melakukan analisis yang baik, maka diperlukan data yang mencakup informasi dan teori konsep dasar yang berkaitan dengan objek yang akan dianalis. Data - data tersebut dapat diklasifikasikan dalam dua jenis data, yaitu data primer Data Primer

\section{a. Data Primer}

Data Primer adalah data yang diperoleh dari lapangan maupun hasil survey yang dapat langsung dipergunakan sebagai sumber dalam analisa struktur. Data Primer antara lain adalah sebagai berikut :

1. Data proyek

Nama Proyek

Fungsi Bangunan : Perkantoran

Jumlah Lantai : 6 lantai

Lokasi : jl.raya imogiri siluk kab. Bantul

StrukturBangunan: Konstruksi Struktur Beton Bertulang

Struktur Atap : Dak beton

Bahan Bangunan : Struktur Beton

2. Data spesifikasi bahan, digunakan untuk mengetahui karakteristik bahan

Pondasi $\quad: \mathrm{f}^{\prime} \mathrm{c}=25 \mathrm{Mpa}$

D Tiang Pancang : $40 \mathrm{~cm}$

3. Data Tanah

Data tanah diperoleh dari hasil penyelidikan dan pengujian tanah

Adalah data tanah Boring

\section{Teknik Analisis Data}

Dalam Proposal penelitian ini, perencanaan menggunakan sistem rangka pemikul momen khusus ( berdasarkan pertimbangan yang telah dijelaskan pada bab sebelumnya) perencanaan meliputi struktur atas dan bawah.

\section{HASIL PENELITIAN DAN PEMBAHASAN \\ Premilinary design}

Berdasarkan SNI 03-2847-2013 Ps. 9.5.2.1 (tabel 9.5(a) . Tebal minimum balok non prategang atau pelat satu arah bila lendutan tidak dihitung $) \mathrm{H}=(1 / 16-$ $1 / 10 \mathrm{~L}), \mathrm{L}=$ panjang bentang balok. Dalam perencanaan ini dipakai 1/12 L Untuk fy selain $420 \mathrm{MPa}$, nilainya harus dikalikan dengan $(0,4+$ fy/700) maka didapatkan

- Balok B1 bentang $7 \mathrm{~m}$ memakai dimensi 40/60 cm

- Balok B2 bentang $6 \mathrm{~m}$ memakai dimensi $35 / 50 \mathrm{~cm}$

- Balok Ba1 bentang $7 \mathrm{~m}$ memakai dimensi 25/35 cm

- Balok Ba2 bentang $6 \mathrm{~m}$ memakai dimensi 20/30 cm

- Pelat lantai memakai tebal $12 \mathrm{~cm}$

- Pelat atap memakai tebal $10 \mathrm{~cm}$

- Tangga memakai tebal $15 \mathrm{~cm}$

- Kolom K1 memakai dimensi 60x60 cm (lantai dasar)

- Kolom K2 memakai dimensi 50x50 cm (lantai 2-6)

\section{Pembebanan}

Pembebanan dalam perencanaan ini memakai peraturan SNI pembebanan 1727 - 2013 untuk beban gempa memakai SNI 1726 - 2012

1. Beban mati, yaitu berat sendiri bangunan yang secara otomatis dihitung oleh program (berupa berat sendiri balok, kolom, dan pelat).

Beban mati tambahan pada pelat lantai sebagai berikut:

a. Berat spesi lantai $2 \mathrm{~cm}=2 \times 21=42 \mathrm{Kg} / \mathrm{m}^{2}$

b. Berat keramik $=1 \times 24=24 \mathrm{Kg} / \mathrm{m}^{2}$

c. Beban plafon $\quad=1 \times 18=18 \mathrm{Kg} / \mathrm{m}^{2}$

d. Beban Partisi = $=74 \mathrm{Kg} / \mathrm{m}^{2}$

e. Beban kabel tray $\quad=1 \times 30=30 \mathrm{Kg} / \mathrm{m}^{2}$

2. Beban Hidup

a) Beban hidup Lantai $\quad=245 \mathrm{Kg} / \mathrm{m}^{2}$

b) Beban Hidup Tangga $=245 \mathrm{Kg} / \mathrm{m}^{2}$

c) Beban Hidup Atap $\quad=135 \mathrm{Kg} / \mathrm{m}^{2}$

3. Beban gempa

Berdasarkan data tanah yang digunakan, klasifikasi situs pada lokasi tersebut termasuk kelas situs SE (tanah lunak). Untuk menentukan spektrum respon desain lokasi tersebut (Kab Bantul) data yang diperlukan adalah:

a. Percepatan batuan dasar pada periode pendek, $S S=1,659 \mathrm{~g}$

b. Percepatan batuan dasar pada periode 1 detik, $S 1=0,574 \mathrm{~g}$

c. Faktor amplifikasi getaran percepatan pada getaran periode pendek, $F a=0,9$

d. Faktor amplifikasi getaran percepatan pada getaran periode 1 detik, $F v=2,4$

e. Parameter spektrum respon percepatan pada periode pendek, $S M S=F a S S=1,493 \mathrm{~g}$

f. Parameter spektrum respon percepatan pada periode 1 detik, $S M 1=F v S 1=1,378 g$

g. Parameter percepatan spektral desain untuk periode pendek, $S D S=23 / S M S=0,995 \mathrm{~g}$

h. Parameter percepatan spektral desain untuk periode 1 detik, $S D 1=23 / S M 1=0,918 \mathrm{~g}$

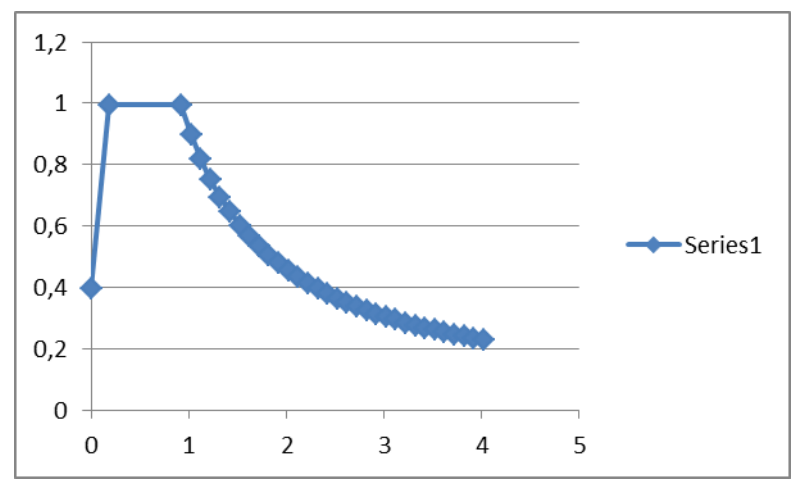

Gambar 1 respons spektrum

Sumber: Hasil Pengolahan data 
Setelah grafik respon spektrum dimasukkan hal yang perlu dilakukan adalah mencari Faktor pengali gempa dengan rumus ;

$$
\begin{aligned}
& \text { Sf } \quad=\mathrm{I} \cdot \mathrm{g} / \mathrm{R} \\
& \text { Sf } \quad=I . g / R \\
& \text { Sf } \quad=1.9,81 / 8 \\
& =1,226
\end{aligned}
$$

\section{Beban Angin}

Untuk desain beban angin dalam perencanaan gedung ini terdapat 2 tipe :

1. Tipe 1 bentang $6 \mathrm{~m}=0,77 \mathrm{kN} / \mathrm{m}^{2} \times(6 \times 3,5)=16,17$ $\mathrm{kN} / \mathrm{m}^{2}$

2. Tipe 2 bentang $7 \mathrm{~m}=0,77 \mathrm{kN} / \mathrm{m}^{2} \times(7 \times 3,5)=18,86$ $\mathrm{kN} / \mathrm{m}^{2}$

\section{Pemodelan}

Analisa struktur terhadap struktur bangunan ini, menggunakan asumsi bahwa sistem merupakan modal space frame (3D frame system). Oleh karena itu elemenelemen struktur dirancang dengan 6 derajat kebebasan pada kedua ujung modal elemen (UX, UY, UZ \# 0 dan RX, RY, RZ \#0)

Permodelan gedung dapat dilihat padagambar yang merupakan capture dari SAP 2000 vs 14.

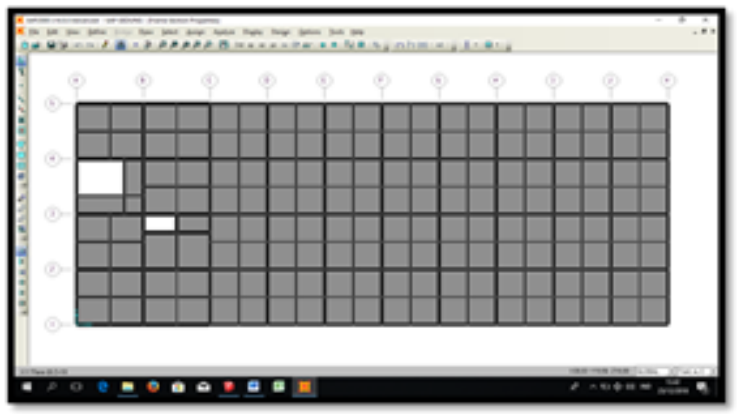

Gambar 2 Permodalan struktur arah X,Y Sumber : SAP vs 14

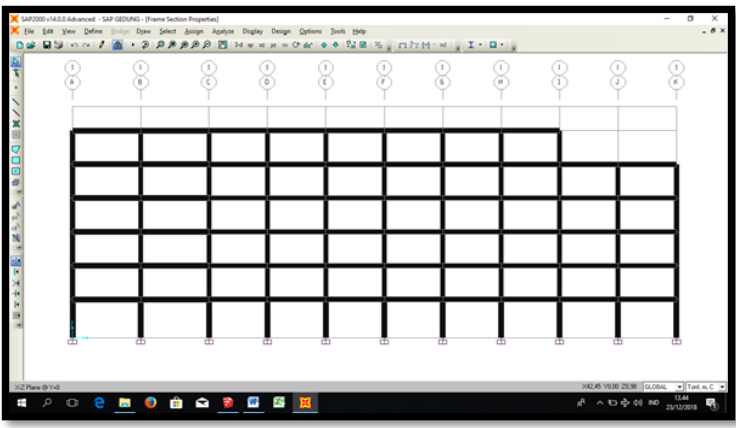

Gambar 3 Permodalan struktur arah X,Z Sumber : SAP vs 14

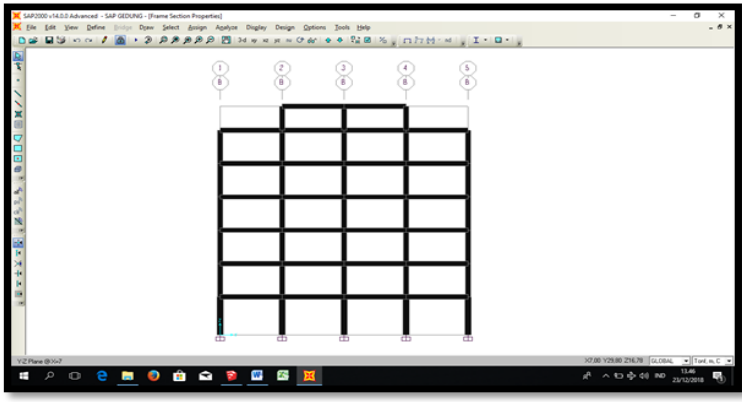

Gambar 4 Permodalan struktur arah Y,Z Sumber : SAP vs 14

\subsection{Perhitungan Pembesian}

1. Ketentuan Material Rangka Pemikul Momen Khusus (SRPMK)

Penggunaan mutu material beton yang digunakan dalam struktur pemikul beban gempa SRPMK ditentukan dalam SNI 2847:2013 Pasal 21.1.4 bahwa kuat tekan beton $f^{\prime} c$ tidak boleh kurang dari $20 \mathrm{MPa}\left(f^{\prime} c=30 \mathrm{MPa}\right)$.

Persyaratan mutu tulangan untuk SRPMK yang dijelaskan dalam Pasal 21.1.5 menyatakan bahwa tulangan pemikul lentur dan aksial atau kombinasi keduanya yang timbul akibat beban gempa bumi harus berupa tulangan ulir yang memenuhi ASTM A706M mutu $420 \mathrm{MPa}(f y=420 \mathrm{MPa})$.

\section{Perencanaan Tulangan Balok}

Kuat lentur positif komponen struktur lentur pada muka kolom tidak boleh lebih kecil dari setengah kuat lentur negarifnya pada muka tersebut. Baik kuat lentur negatif maupun positif pada setiap penampang di sepanjang bentang tidak boleh kurang dari seperempat kuat lentur terbesar yang disediakan

$\phi M n+\geq 1 / 2 \phi M n-($ tumpuan $)$

$(\phi M n+\operatorname{atau} \phi M n-) \geq 1 / 4 \phi M n \max ($ tumpuan dan lapangan)

Langkah-langkah desain tulangan lentur antara lain sebagai berikut:

a. Menentukan spesifikasi setiap material

b. Menentukan dimensi-dimensi penampang ( $\mathrm{b} \times \mathrm{h}$ )

c. Menentukan ukuran tulangan pokok dan tulangan geser $\emptyset \mathrm{D}$

d. Menentukan tebal selimut beton $p$

e. Menentukan momen lentur ultimit, u M

f. Menghitung tinggi efektif balok $d$

g. Menghitung rasio penulangan yang diperlukan,

$\rho=0.85 * \mathrm{fc}^{\prime} / \mathrm{fy} *\left[1-\sqrt{ } *\left[1-2 * \mathrm{Rn} /\left(0.85 * \mathrm{fc}{ }^{\prime}\right)\right]=\right.$ 0,0058

$R n=M \quad / \phi b d 2$ 
1) Membandingkan dengan nilai $\rho$ min dan $\rho$ max, $\rho \min =0,25 \sqrt{ } f^{\prime} c$ fy $\rho$ maks $=0,025 \min 1,4 \mathrm{y} / \mathrm{fy}$

2) Perhitungan luas tulangan yang diperlukan, AS perlu $=\rho$ pakai bd

3) Periksa jarak bersih antar tulangan tidak boleh kurang dari 25 mm (SNI 2847-2013 pasal 7.6)

4) Kapasitas tulangan yang terpasang $\phi \mathrm{Mn}>\mathrm{Mu}$,

Dari hasil perhitungan didapatkan pembesian sebagai berikut

3. Perencanaan Tulangan Kolom

Perhitungan penulangan kolom menggunakan program PCA col program ini hanya menghitung Tulangan utama saja, untuk menghitung tulangan geser dan strong kolom weak beam dihitung manual.

a. Data Perencanaan Pcacol

\begin{tabular}{|c|c|}
\hline f'c & $=25$ \\
\hline fy & $=400$ \\
\hline fyø & $=240$ \\
\hline $\mathrm{b}$ & $=600$ \\
\hline $\mathrm{h}$ & $=600$ \\
\hline ts & $=50$ \\
\hline$\Phi$ & $=0.75$ \\
\hline$\varnothing$ Lentur & $=\mathrm{D} 22$ \\
\hline ØSengkang & $=\emptyset 12$ \\
\hline
\end{tabular}

Dari analisa SAP diambil beberapa section kolom untuk mencari kolom yang paling kritis, dalam perencanaan ini section yang paling kritis berada di koordinat B

Tabel 1 Rekap balok

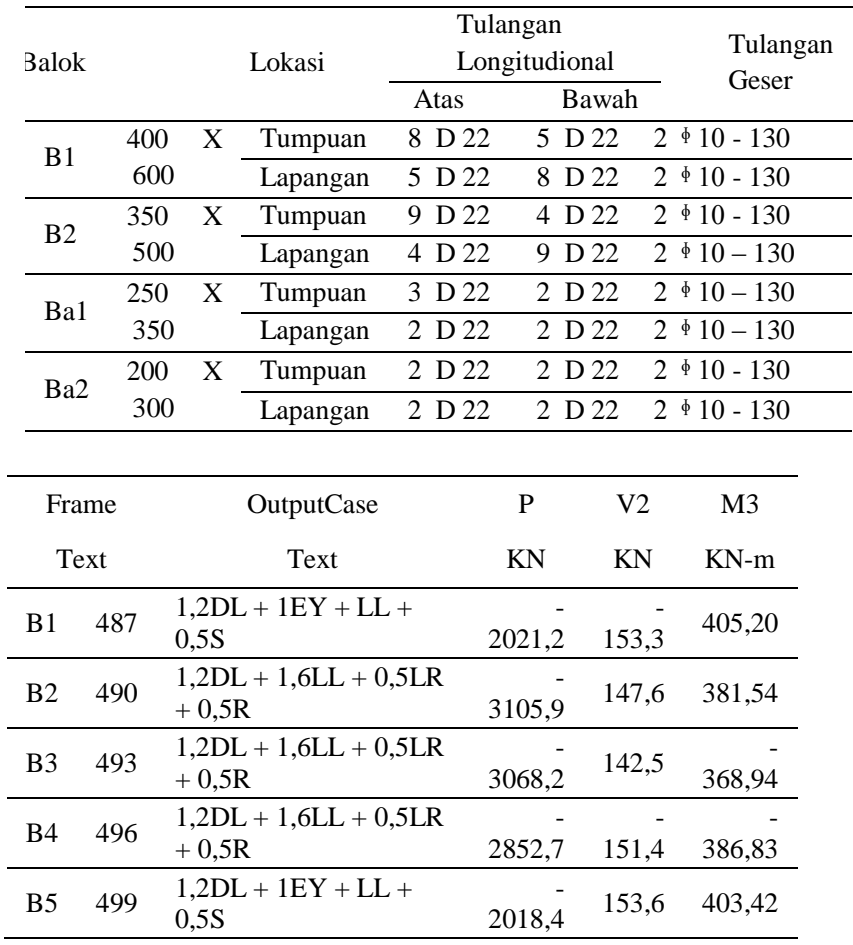

Sumber : Analisa data

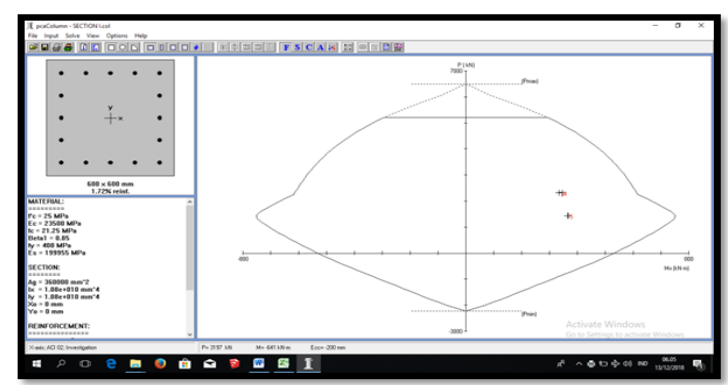

Gambar 5 Diagram interaksi kolom Sumber : SAP vs 14

Perencanaan tulangan transversal kolom berdasarkan SNI 2847:2013 Pasal 21.6.4 dan 21.6.5 adalah sebagai berikut:

b. Menentukan Panjang lo Berdasarkan SNI 2847 tahun 2013 pasal 21.6.4.1, panjang lo ditentukan tidak boleh kurang dari yang terbesar sebagai berikut:

- tinggi penampang kolom $(h k)$

- seperenam panjang bersih kolom ( $16 h n$ )

- $450 \mathrm{~m}$

c. Menentukan Spasi Sepanjang lo Berdasarkan SNI 2847 tahun 2013 pasal 21.6.4.3, spasi tulangan transversal sepanjang lo tidak boleh melebihi yang terkecil sebagai berikut:

- Seperempat tinggi penampang kolom ( $14 h k$ )

- Enam kali diameter tulangan longitudinal $(6 D)$

- $s o=100+350+h \times 3 h \times$ adalah spasi horizontal maksimum pengikat silang.

so tidak boleh melebihi $150 \mathrm{~mm}$ dan tidak perlu lebih kecil dari $100 \mathrm{~mm}$

d. Spasi Diluar Panjang lo Menurut SNI 2847 tahun 2013 pasal 21.6.4.5 diluar panjang lo spasi tulangan transversal tidak melebihi terkecil sebagai berikut:

- Enam kali diameter tulangan longitudinal (6D)

- $150 \mathrm{~mm}$

e. Perhitungan Geser Akibat Gempa

$V e$ tidak perlu lebih besar dari $V e$ yang dihitung berdasarkan $M p r$ balok yang merangkai kolom diujung atas dan bawah.

Menurut SNI 2847 tahun 2013 pasal 21.6.5.2, Vc diasumsikan sama dengan nol bilamana:

- Gaya geser akibat gempa Ve mewakili setengah atau lebih dari kekuatan geser perlu maksimum.

- Gaya tekan aksial terfaktor Pu kurang dari $A g f c^{\prime} / 10$.

Perhitungan Tulangan Geser Sepanjang $l 0$

Ash $1=\left(0,3 s b c f c^{\prime} / f y t\right) *($ Ag Ach -1$)$

Ash $2=0,09 s b c f c^{\prime} / f y$

Ach = luas penampang inti beton

$b c=$ lebar penampang inti terkekang

Maka didapatkan dimensi kolom

$\mathrm{K} 1=600 \times 600$ dengan tulangan $16 \mathrm{D} 25$

$\mathrm{K} 2=600 \times 600$ dengan tulangan 16 D22 
4. Perencanaan Pondasi

a. Data tanah

Tabel 2 Data tanah

\begin{tabular}{|c|c|c|c|c|}
\hline \multicolumn{3}{|c|}{ DATA HASIL PENGUJIAN } & HASIL LAB & SPT \\
\hline \multirow{2}{*}{ No } & \multicolumn{2}{|c|}{ Kedalaman } & \multirow{2}{*}{ Jenis Tanah } & \multirow{2}{*}{$\frac{\text { Nilai SPT }}{\mathrm{N}}$} \\
\hline & $\mathrm{z}_{1}(\mathrm{~m})$ & $\mathrm{z}_{2}(\mathrm{~m})$ & & \\
\hline 1 & 0,00 & 5,00 & lempung & 5 \\
\hline 2 & 5,00 & 10,00 & lempung & 9 \\
\hline 3 & 10,00 & 15,00 & lempung & 11 \\
\hline 4 & 15,00 & 20,00 & lemp. padat & 21 \\
\hline 5 & 20,00 & 25,00 & lemp. pasir & 63 \\
\hline
\end{tabular}

Sumber : Hasil uji lab

b. Data Bahan

Jenis tiang pancang : Beton bertulang tampang lingkaran Diameter tiang pancang,

$$
\mathrm{D}=0,4 \mathrm{~m}
$$

Panjang tiang pancang,

$$
\mathrm{L} \quad=22 \mathrm{~m}
$$

Kuat tekan beton tiang pancang, $\mathrm{fc}^{\prime} \quad=25 \mathrm{Mpa}$

Berat beton bertulang, $\quad \mathrm{wc}=24 \mathrm{kN} / \mathrm{m}^{3}$

c. Tahanan Aksial Tiang Pancang

- Berdasarkan Kekuatan bahan

- Berdasarkan Hasil Uji SPT (Mayerhoff)

(diambil hasil terkecil )

d. Tahanan Leteral Tiang Pancang

Berdasarkan defleksi Tiang Maksimum (Broms)

Tahanan lateral tiang $(\mathrm{H})$ kategori tiang panjang, dapat dihitung dengan persamaan :

$\mathrm{H}=$ yo $* \mathrm{kh} * \mathrm{D} /[2 * \mathrm{~b} *(\mathrm{e} * \mathrm{~b}+1)]$

dengan, $\mathrm{b}=[\mathrm{kh} * \mathrm{D} /(4 * \mathrm{Ec} * \mathrm{Ic})] 0.25$

e. Perhitungan Kekuatan Pondasi

\begin{tabular}{|c|c|c|c|c|c|c|c|c|}
\hline \multicolumn{4}{|c|}{ Susunan tiang pancang arah $\mathrm{x}$ : } & \multicolumn{5}{|c|}{ Susunan tiang pancang arah y : } \\
\hline No. & Jumlah & $\mathrm{x}$ & $\mathrm{n} * \mathrm{x}^{2}$ & No. & Jumlah & $\mathrm{y}$ & $\mathrm{n} * \mathrm{y}^{2}$ & \\
\hline & $\mathrm{n}$ & (m) & $\left(\mathrm{m}^{2}\right)$ & & $\mathrm{n}$ & (m) & $\left(\mathrm{m}^{2}\right)$ & \\
\hline 1 & 3 & 0,80 & 1,92 & 1 & 3 & 0,80 & 1,92 & \\
\hline 2 & 3 & 0,00 & 0,00 & 2 & 3 & 0,00 & 0,00 & \\
\hline 3 & 3 & $-0,80$ & 1,92 & 3 & 3 & $-0,80$ & 1,92 & \\
\hline $\mathrm{n}=$ & 9 & $\sum x^{2}=$ & 3,84 & $\mathrm{n}=$ & 9 & $\sum y^{2}=$ & 3,84 & \\
\hline \multicolumn{4}{|c|}{ Lebar pilecap arah $\mathrm{x}$, } & & & $\mathrm{L}_{\mathrm{x}}=$ & 1,60 & $\mathrm{~m}$ \\
\hline \multicolumn{4}{|c|}{ Lebar pilecap arah y, } & & & $\mathrm{L}_{\mathrm{y}}=$ & 1,60 & $\mathrm{~m}$ \\
\hline
\end{tabular}

Tabel 3 Susunan Tiang pancang

Sumber : Analisa data

Syarat : Humax $\leq \phi * \mathrm{Hn}$

$$
24,69 \leq 42 \rightarrow
$$

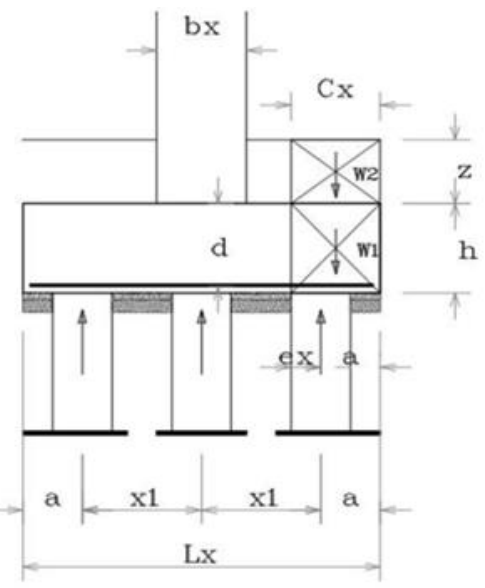

Gambar 6 Tinjauan Geser Arah X

$\phi * \mathrm{Vc} \geq \mathrm{Vux}$

$2080>1045,65 \rightarrow \quad(\mathbf{O K})$

Tinjauan Geser 2 Arah Pons

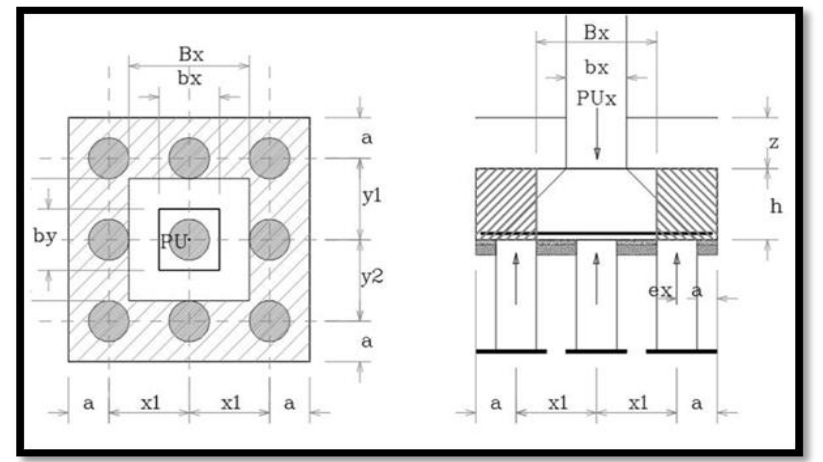

Gambar 7 Tinjauan Geser Arah X

Syarat :

$\phi^{*}$ Vnp $\geq$ Puk

$3520,83>3105,86 \rightarrow \quad(\mathbf{O K})$

Tabel 4 Rekap Tiang pancang

\begin{tabular}{llllllll}
\hline \multirow{2}{*}{$\begin{array}{l}\text { Tipe } \\
\text { Pond } \\
\text { asi }\end{array}$} & \multicolumn{2}{c}{ Dimensi Pile Cap } & \multicolumn{5}{c}{ Tiang pancang } \\
\cline { 2 - 8 } & $\mathrm{b}$ & $\mathrm{h}$ & $\mathrm{t}$ & $\mathrm{D}$ & $\mathrm{x}$ & $\mathrm{y}$ & $\begin{array}{c}\text { Juml } \\
\mathrm{ah}\end{array}$ \\
\hline $\mathrm{P} 1$ & 2,4 & 2,4 & 0,7 & 0,4 & 3 & 3 & 9 \\
\hline $\mathrm{P} 2$ & 2,4 & 2,4 & 0,7 & 0,4 & 3 & 3 & 7 \\
\hline $\mathrm{P} 3$ & 2,4 & 2,4 & 0,7 & 0,4 & 2 & 3 & 6 \\
\hline P4 & 2,4 & 2,4 & 0,7 & 0,4 & 2 & 2 & 5 \\
\hline
\end{tabular}

Sumber : Analisa Data 


\section{Kesimpulan}

Dari hasil analisis perencanaan ini dapat diambil beberapa kesimpulan seperti berikut ini:

1. Lokasi perencanaan gedung termasuk dalam kategori desain seismik D (KDS D) sehingga komponen struktur rangka gempa harus menggunakan sistem rrangka pemikul momen khusus (SRPMK) berdasarkan SNI $2847-2012$

2. Digunakan dimensi komponen struktur gedung sebagai berikut:

a) Balok Induk $40 \mathrm{~cm} \times 60 \mathrm{~cm}$ (Bentang 7,0 meter) rasio 2,06

b) Balok Induk $35 \mathrm{~cm} \times 50 \mathrm{~cm}$ (Bentang 7,0 meter) rasio 2,17

c) Balok Anak $25 \mathrm{~cm}$ x $35 \mathrm{~cm}$ (Bentang 3,5 meter) rasio 2,17

d) Balok Anak $20 \mathrm{~cm} \times 30 \mathrm{~cm}$ (Bentang 3,0 meter) rasio 2,53

e) Kolom $60 \mathrm{~cm}$ x $60 \mathrm{~cm}$ untuk Lantai dasar rasio 2,18

f) Kolom $50 \mathrm{~cm}$ x $50 \mathrm{~cm}$ untuk Lantai 1-6 rasio 2,43

g) Sloof $35 \times 50 \mathrm{~cm}$ rasio 2,17

3. Digunakan pelat lantai dengan tebal $12 \mathrm{~cm}$ untuk lantai 1-6 dan untuk atap digunakan tebal pelat $10 \mathrm{~cm}$

4. Pondasi Menggunakan Tiang Pancang

\section{Saran}

Berdasarkan Kesimpulan perencanaan gedung ini, maka penulis merekomendasikan berupa saran-saran sebagai berikut :

1. Dalam perencanaan bangunan sebaiknya menggunakan peraturan SNI yang terbaru, untuk saat ini seperti :

- Beban minimum untuk perancangan bangunan gedung dan struktur lain berdasarkan SNI 1727 - 2013

- Tata cara perencanaan ketahanan gempa untuk gedung berdasarkan SNI 1726 - 2012

- Persyaratan beton struktural untuk bangunan gedung berdasarkan Sni 2847 - 2013

2. Dalam perencanaan dimensi awal sebaiknya dilakukan estimasi terlebih dahulu agar tidak terjadi perubahan dimensi saat dilakukan analisis struktur.

\section{DAFTAR PUSTAKA}

Asroni Ali, MT, 2010 Balok dan pelat beton bertulang: graham ilmu

Badan Standarisasi Nasional. 2012. Tata Cara Perencanaan Ketahanan Gempa untuk Struktur Bangunan Gedung dan Non Gedung (SNI 1726:2012). Jakarta.

Badan Standarisasi Nasional. 2013. Peraturan pembebanan Indonesia untuk gedung dan bangunan lain (SNI 1727:2013). Jakarta.

Badan Standarisasi Nasional. 2013. Persyaratan Beton Struktural untuk Bangunan Gedung (SNI 2847:2013). Jakarta.

Budianto.dkk. 2015. Perhitungan Gedung 10 lanai dengan Perencanaan Sistem Rangka Pemikul Momen Khusus (SRPMK) di Jalan Sepakat II Kota Pontianak. Pontianak
Departemen Pekerjaan Umum. 1987. Pedoman Perencanaan Pembebanan untuk Rumah dan Gedung. Jakarta.

Heryanto. 2009. Perhitungan Struktur Hotel 11 Lantai dengan Struktur Beton Bertulang di Pontianak. Pontianak.

Imran, Iswandi. 2014. Perencanaan Lanjut Struktur Beton Bertulang. ITB : Bandung

M. Ilham Gumilang.dkk. 2016 Perencanaan Pondasi Tiang Pancang Dengan Memperhitungkan Pengaruh Likuifaksi Pada Proyek Pembangunan Hotel Di Lombok : Jurusan Teknik Sipil FTSP ITS

Purwono, Rachmat. 2009. Perencanaan Struktur Beton Bertulang Tahan Gempa. Surabaya: tspress.

Setiawan, Agus. 2016. Perancangan Struktur Beton Bertulang Berdasarkan SNI 2847:2013. Jakarta: Erlangga.

Wahyudi, Herman. 2013. Daya Dukung Pondasi Dalam. Surabaya : Jurusan Teknik Sipil FTSP - ITS. 